\title{
Intrinsic Pressor Activity of Midaglizole, an Alpha-2 Adrenoceptor Antagonist, in Pithed Rats
}

\author{
Masaaki HIROHASHI, Kiyoshi TAMURA and Akira AKASHI \\ Research Institute, Daiichi Pharmaceutical Co., Ltd., \\ 16-13, Kita-kasai, 1 -Chome. Edogawa-ku, Tokyo 134, Japan
}

Accepted June 1, 1990

\begin{abstract}
Midaglizole ( 3 and $30 \mathrm{mg} / \mathrm{kg}$. i.v.) increased blood pressure in pithed rats. The pressor response was not inhibited by intravenous prazosin $10.3 \mathrm{mg} /$ $\mathrm{kg})$, yohimbine $(1 \mathrm{mg} / \mathrm{kg})$, ketanserin $(1 \mathrm{mg} / \mathrm{kg})$ or diphenhydramine $(5 \mathrm{mg} / \mathrm{kg})$. Diltiazem (1 $\mathrm{mg} / \mathrm{kg}$ ) antagonized the hypertension. Idazoxan $(10 \mathrm{mg} / \mathrm{kg}$ ) also increased blood pressure, and the pressor response was inhibited by prazosin, but not by yohimbine. These results suggest that the vascular effect of midaglizole is due to a mechanism different from that of idazoxan.
\end{abstract}

Midaglizole (DG-5128) has been reported to have hypoglycemic (1) and anti-asthmatic (2) activities, which were attributed to its alpha-2 adrenoceptor blocking activities. Muramatsu et al. (3) showed that midaglizole has selective alpha-2 adrenoceptor blocking activities in the canine mesenteric artery and the rat vas deferens. A selective alpha-2

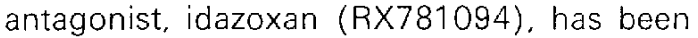
reported to produce an intrinsic pressor response in pithed rats, and these effects were antagonized by prazosin (4, 5). Midaglizole also increased the blood pressure in pithed rats. The present study was performed to investigate the mechanism of the pressor activity of midaglizole in comparison with that of idazoxan.

Male Wistar rats $(290-450 \mathrm{~g})$ were anesthetized with pentobarbital sodium $(35 \mathrm{mg} /$ $\mathrm{kg}$. i.p.) and artificially ventilated with room air. Systemic arterial pressure was measured with a pressure transducer via a cannula inserted into the right carotid artery and recorded on a polygraph. Pithing was performed by introducing a steel rod ( $2 \mathrm{~mm}$ in diameter) from the orbit into the spinal canal. Antagonists were intravenously injected $15 \mathrm{~min}$ before the intravenous administration of midaglizole or idazoxan. Statistical evaluation of the data was performed with the method of one-way layout and multiple comparison by Scheffé.

Diastolic blood pressure before the ad- ministration of the compounds was about 35 $\mathrm{mmHg}$. Midaglizole at doses of 3 and $30 \mathrm{mg} /$ $\mathrm{kg}$ produced an increase in blood pressure by 27 and $64 \mathrm{mmHg}$, respectively, at approximately $1 \mathrm{~min}$ after the administration. The increase was transient, and it reduced to 8 and $33 \mathrm{mmHg}$ at $5 \mathrm{~min}$ after the administration. Yohimbine $(1 \mathrm{mg} / \mathrm{kg}$ ) and diltiazem (1 $\mathrm{mg} /$ $\mathrm{kg}$ ) decreased blood pressure by about 10 and $15 \mathrm{mmHg}$, respectively. The effect of diltiazem was quite long-lasting. Diphenhydramine $(5 \mathrm{mg} / \mathrm{kg}$ ) increased blood pressure by $25 \mathrm{mmHg}$. Before the alpha- 2 antagonist administration, however, these changes almost returned to the initial level. Prazosin $(0.3$ $\mathrm{mg} / \mathrm{kg}$ ) and ketanserin $(1 \mathrm{mg} / \mathrm{kg})$ had little or no effect on blood pressure. The pressor effect of midaglizole was not inhibited after pretreatment with prazosin, yohimbine, ketanserin or diphenhydramine. Diltiazem significantly antagonized the pressor response to midaglizole (Fig. 1). These results suggest that the pressor response to midaglizole was not mediated by alpha- 1 or alpha- 2 adrenoceptors, by serotonin-2 receptors or histamine- 1 receptors. As the pressor response to midaglizole was antagonized by the calcium entry blocker diltiazem, the drug seems to cause an influx of extracellular calcium, especially via voltage-dependent calcium channels, and induce contraction of the blood vessels. Idazoxan $(10 \mathrm{mg} / \mathrm{kg})$ also produced a tran- 
INCREASE IN DIASTOLIC BLOOD PRESSURE $(\triangle \mathrm{mmHg})$

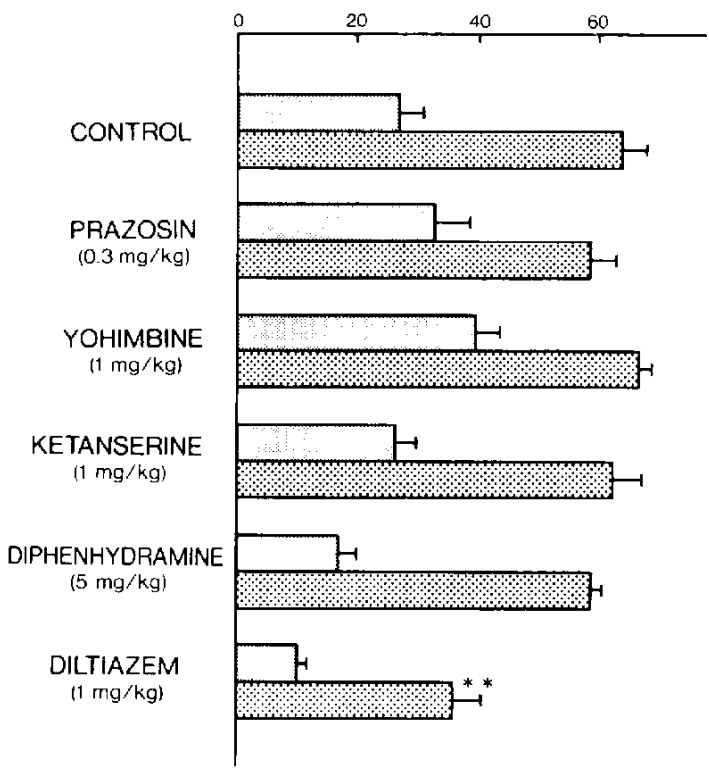

Fig. 1. Influence of several antagonists on the pressor responses to midaglizole in pithed rats. Each column and bar represents the mean and standard error of 5-7 animals, respectively. **: Significantly different from the control $(P<0.01)$. $\square$ : Midaglizole. $3 \mathrm{mg} / \mathrm{kg}$, i.v. Haj: Midaglizole. $10 \mathrm{mg} /$ kg, i.v.
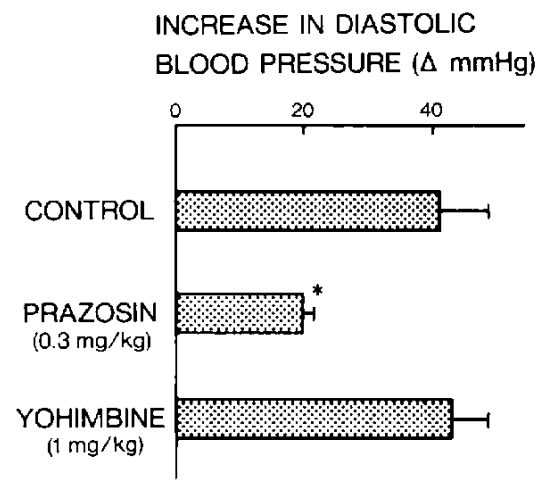

Fig. 2. Influence of several antagonists on the pressor response to idazoxan in pithed rats. Each column and bar represents the mean and standard error of 5-7 animals, respectively. *: Significantly different from the control $(P<0.05)$. $;: ;$ : Idazoxan. $10 \mathrm{mg} / \mathrm{kg}$, i.v sient increase in blood pressure, similarly to midaglizole. In contrast with midaglizole. however, the pressor response to idazoxan was inhibited by prazosin, but not by yohimbine (Fig. 2). The present results agree with the reported findings on idazoxan $(4,5)$ and suggest that the mechanism of the pressor response to midaglizole differs from that of idazoxan.

\section{References}

1 Kameda, K., Ono, S. and Abiko, Y.: Hypoglycemic action of 2-[2-(4,5-dihydro-1 $\mathrm{H}$-imidazol-2-yl)1 -phenylethyl]pyridine dihydrochloride sesquihydrate (DG-5128), a new hypoglycemic agent. Arzneimittelforschung 32, 39-44 (1982)

2 Yoshie, Y., lizuka, K., Umegae, Y., Kobayashi, S. and Nakazawa, T.: Inhibitory effect of alpha-2 adrenoceptor antagonist (DG-5128) on intractable asthma. Allergy 36, 413-416 (1987)

3 Muramatsu, I., Oshita, M. and Yamanaka, K.: Selective alpha- 2 blocking action of DG-5128 in the dog mesenteric artery and rat vas deferens. J. Pharmacol. Exp. Ther. 227, 194-198 (1983)

4 Paciorek, P.M. and Shepperson, N.B.: Alpha-1 adrenoceptor agonist activity of alpha-2 adrenoceptor antagonists in the pithed rat preparation. Br. J. Pharmacol. 79, 12-14 (1983)

5 Timmermans, P.B.M.W.M., Qian, J.Q., Ruffolo, R.R., Jr. and Van Zwieten, P.A.: A study of the selectivity and potency of rauwolscine. RX781094 and RS21361 as antagonists of alpha-1 and alpha-2 adrenoceptors. J. Pharmacol. Exp. Ther. 228, 739-748 (1984) 